\section{Commentary: Cannulation and exchange of extracorporeal membrane oxygenation cannula: An essential skill for surgeons!}

\author{
Chih-Hsien Wang, MD, PhD, and \\ Shu-Chien Huang, MD, PhD
}

The use of adult cardiac extracorporeal membrane oxygenation (ECMO) support has risen rapidly. ${ }^{1}$ Advances in the devices and knowledge has significantly extended the duration of both cardiac and respiratory ECMO support. ${ }^{2}$ Because ECMO is used for relatively long periods, effective management of ECMO-related complications is crucial. In this issue of the Journal, Abdullah and colleagues ${ }^{3}$ provide a method for an awake, percutaneous, bedside ECMO arterial cannula exchange. The cannula was exchanged using a "through-the-guidewire" technique.

Conventional cardiac surgical training mostly emphasizes open surgical techniques; however, in the current era, the percutaneous guidewire technique merits increased attention. The performance of mini-invasive surgery, initiation of ECMO support, and exchange of ECMO cannula at the bedside, as reported in this case, could all be accomplished using less-invasive techniques. The authors also provided a video, which can serve as a clear and educational resource for the surgeons.

The authors punctured the cannula and inserted the guidewire. Although it is a useful technique, some potential drawbacks to this approach should be noted. First, the guidewire may run through the side-hole of canula and possibly be jailed with the cannula,

From the Department of Surgery, National Taiwan University Hospital, National Taiwan University College of Medicine, Taipei, Taiwan.

Disclosures: The authors reported no conflicts of interest.

The Journal policy requires editors and reviewers to disclose conflicts of interest and to decline handling or reviewing manuscripts for which they may have a conflict of interest. The editors and reviewers of this article have no conflicts of interest.

Received for publication March 19, 2020; revisions received March 19, 2020; accepted for publication March 21, 2020; available ahead of print April 2, 2020.

Address for reprints: Shu-Chien Huang, MD, PhD, Department of Surgery, National

Taiwan University Hospital, 7 Chung-Shan South Rd, Taipei 100, Taiwan (E-mail:

cvshuang@gmail.com).

JTCVS Techniques 2020;2:90-1

2666-2507

Copyright $@ 2020$ The Authors. Published by Elsevier Inc. on behalf of The American Association for Thoracic Surgery. This is an open access article under the CC BY-NCND license (http://creativecommons.org/licenses/by-nc-nd/4.0/).

https://doi.org/10.1016/j.xjtc.2020.03.021

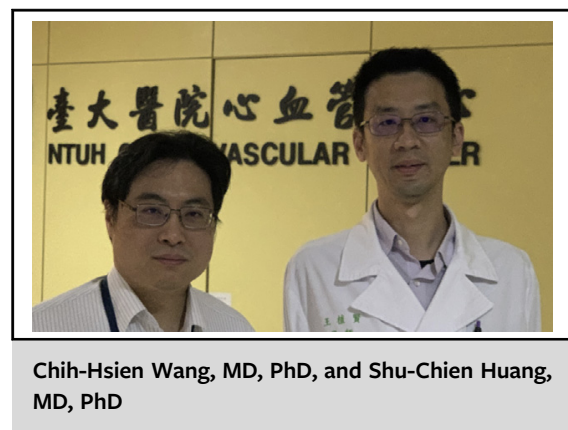

CENTRAL MESSAGE

Teaching the techniques for cannulating and exchanging the cannula for extracorporeal circulation support are indispensable in cardiac surgical training!

preventing the old cannula from being pulled out smoothly (Figure 1).

Second, if a thrombus forms at the tip end of the old cannula, the guidewire may not enter smoothly. Third, the hole on the cannula could cause bleeding if the exchange failed and resumption of ECMO flow is needed.

To address the aforementioned risks, our team applies the following methods to exchange a cannula: (1) clamp the circuit and disconnect the tubing from the connector of the cannula, (2) use a Fogarty catheter to perform a thrombectomy first if thrombus is suspected, and (3) insert the

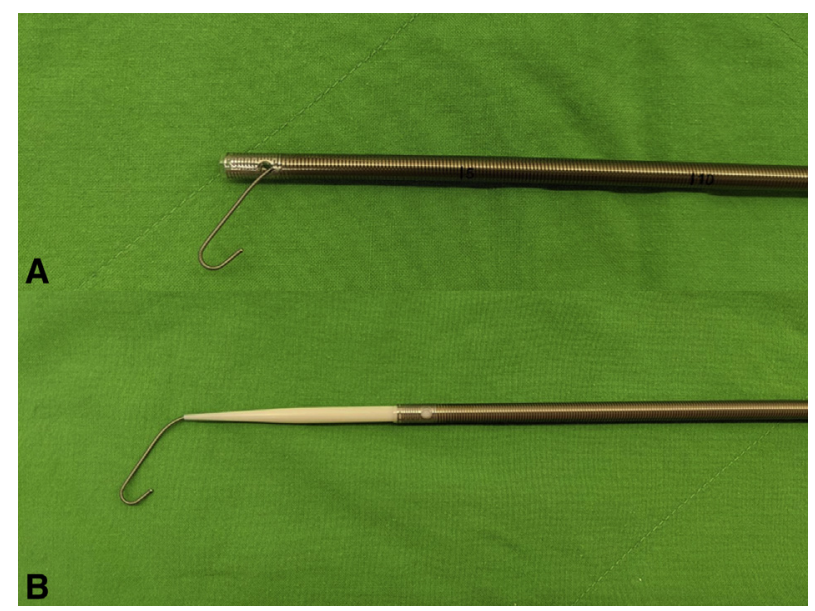

FIGURE 1. A, Guidewire passing through a side-hole of a cannula. B, Using an introducer inside the cannula could prevent this complication. 
white introducer of the ECMO cannula into the cannula before the guidewire, thereby preventing the guidewire from running through of the side-hole.

In summary, the authors offer a creative approach to rapidly exchanging an ECMO cannula at the bedside. The video is informative and helpful for teaching. Mechanical circulatory support is one of the most rapidly evolving fields in cardiac surgery; the sharing of techniques and special conditions in ECMO care is paramount.

\section{References}

1. Guglin M, Zucker MJ, Bazan VM, Bozkurt B, El Banayosy A, Estep JD, et al Venoarterial ECMO for adults: JACC scientific expert panel. J Am Coll Cardiol. 2019;73:698-716

2. Smith M, Vukomanovic A, Brodie D, Thiagarajan R, Rycus P, Buscher H. Duration of veno-arterial extracorporeal life support (VA ECMO) and outcome: an analysis of the Extracorporeal Life Support Organization (ELSO) registry. Crit Care. 2017;21:45.

3. Abdullah M, Shah A, Madathil RJ, Kacsorowski D. Awake, percutaneous, bedside extracorporeal membrane oxygenator arterial cannula exchange. $J$ Thorac Cardiovasc Surg Tech. 2020;2:84-5. 